Article

\title{
Study on the Evolution of Water Resource Utilization Efficiency in Tibet Autonomous Region and Four Provinces in Tibetan Areas under Double Control Action
}

\author{
Xuhui Ding * ${ }^{-}$, Zixuan Zhang, Fengping Wu and Xiangyi Xu \\ School of Business Administration, Hohai University, Changzhou 213022, China; zzx990121@163.com (Z.Z.); \\ wfp@hhu.edu.cn (F.W.); m15161189115@163.com (X.X.) \\ * Correspondence: dingxh@hhu.edu.cn
}

Received: 18 May 2019; Accepted: 14 June 2019; Published: 20 June 2019

check for updates

\begin{abstract}
Tibet is the province with the largest international rivers and water resource reserves in China. However, due to its special ecological environment, the utilization of water resources has become an inevitable problem. Considering the undesirable outputs in water resource utilization, the Super-efficiency Slack-based Measure (SE-SBM) model is used to measure water utilization efficiency of Tibet and the Tibetan areas (four provinces where Tibetan areas are located) from 2006 to 2016. The mixed and random panel Tobit model is used to investigate the driving factors of water efficiency and a horizontal comparison between provinces is made on this basis. The results show that the water utilization efficiency of Tibet and the Tibetan areas in four provinces shows a "U-shaped" trend. The water utilization efficiency of most provinces is greater than or close to 1 and the water utilization efficiency of each province shows a constant convergence trend. Environmental regulation and technological innovation have a significant positive effect on water utilization efficiency. Urbanization and foreign direct investment (FDI) have a significant negative effect on water utilization efficiency. Per capita Gross Domestic Product (GDP) and water resource endowment have no significant effect on water utilization efficiency. It is necessary to select a new type of urbanization suitable for the Tibetan Plateau, eliminate the backward production capacity, high water consumption, or high emissions industries, and to strengthen the research and development of water-saving and emission-reduction technology innovation in Tibet.
\end{abstract}

Keywords: water utilization efficiency; Tibet Autonomous Region; dual control action; SE-SBM

\section{Introduction}

At present, the issues of water shortage, water pollution, and deterioration of water's ecological environment are serious in China; these have become major problems restricting the sustainable development of the economy and society. The "Opinions on Implementing the Strictest Water Resources Management System" promulgated by the State Council in 2012 proposed three red lines, including the water resource development and utilization control red line, the water efficiency control red line, and the water function area limit pollution red line [1]. The water resources and per capita water resources of the Tibet Autonomous Region have always ranked first in China. However, due to the special climatic conditions, geological conditions, and economic agglomeration of the plateau, the problem of water pollution in population agglomerations has become increasingly serious. Engineering water shortages make it difficult to meet the needs of economic and social development [2]. In 2016, the average Gross Domestic Product (GDP) per cubic meter of water in the Tibet Autonomous Region was only $37.02 \mathrm{CNY}$, which was only $28.66 \%$ of the national average. The water consumption per 
$10,000 \mathrm{CNY}$ of industrial output was as high as 173.53 cubic meters, which was 3.78 times the national average. The per capita water consumption is 949.6 cubic meters per person, ranking second in China. Due to the special geography of the Tibet Autonomous Region, water resource utilization is not only the core issue of the coordinated development between people and nature in Tibetan areas, but also affects major strategic issues such as sustainable development, cross-border ecological security, and biodiversity conservation in China and neighboring countries [3,4]. Improving water utilization efficiency of associated sectors such as agriculture, industry, and residential consumption is considered to be one potential solution to the water scarcity problem $[5,6]$.

Faced with the increasingly severe water resources situation, water utilization efficiency has attracted more and more attention from the academic community. The research objects include agricultural irrigation, industrial enterprises, key cities, etc. The research methods also involve the stochastic frontier method, the data envelopment analysis method, principal component analysis, etc. [7,8]. Ding et al., and Sun et al., considered the undesirable output evaluation of water utilization efficiency in the production process and found that the water utilization efficiency of various provinces and regions in China showed a significant U-shaped trend $[9,10]$. Lu et al. used the three-stage Data Envelope Analysis (DEA) model to measure the water efficiency of the Yangtze River economic belt, and proposed that the mean of the technical efficiency and that of the comprehensive technical efficiency were underestimated and the mean of the scale efficiency was overestimated [11]. The absence of an effective, scientific evaluation method may lead to a lack of awareness of sustainable water usage. Zhang, et al. selected six indicators to construct an evaluation index system of sustainable water management [12]. Woodward et al. established a water efficiency evaluation framework in infrastructure investments and applied this to three federal campuses [13].

In response to the driving factors of water utilization efficiency, scholars have given theoretical explanations and empirical tests from the perspectives of urbanization, environmental regulation, industrial agglomeration, and resource endowment [14,15]. Nazari recognized legal, social, technological, and political dynamics as the major reasons for failure of irrigation water management in Iran [16]. Sun et al. proposed that China's "four modernizations", i.e., new industrialization, urbanization, informationization, and agriculture modernization, have not been completely positively correlated with water resource efficiency [17]. While Ma proposed that the positive effects of technological progress, urbanization, and per capita GDP were significant, the lack of management and production scale severely restricted the further improvement of water resource efficiency when exploring the impact of Xinjiang urbanization on water resource utilization efficiency [18]. Due to the notable spatial correlation characteristics of water consumption efficiency among different provinces in China, Bao proposed that the per capita GDP and urbanization levels of itself and its neighboring provinces have the most prominent positive effects on water efficiency [19].

The existing research measured water efficiency in a variety of ways, while partly considering undesirable outputs. Some experts also explored the driving factors of water use efficiency and spatial spillover effects. However, previous studies paid less attention to Tibet and failed to recognize the importance of water resource utilization in Tibet and the Tibetan areas in four provinces in China and neighboring countries. A small number of studies involving Tibetan areas only used water intensity as a characterization of their water resource utilization efficiency, but failed to consider the further distinction between undesirable output in water utilization and effective decision-making units, which is the work of this paper. This will have important practical significance for rationally formulating water utilization policies and improving water utilization efficiency.

\section{Model Selection and Construction}

\subsection{SE-SBM Model}

Data Envelopment Analysis (DEA) is a non-parametric technical efficiency analysis method based on the relative comparison among the evaluated objects, which can ignore the specific function form 
and standardization of data disposal [20]. The DEA model was proposed by American logician Charnes et al., 1978, and Tone Kaoru, 2001, proposed the Slack Based Measure (SBM) model. The SBM model is a DEA model considering relaxation improvement, which can solve the problem that the radial model does not include relaxation variables in the inefficient measurement. The SE-SBM model also solves the problem of distinguishing the efficiency of effective Decision Making Unit (DMU), while the undesirable output model also incorporates "bad" output into the measurement system [21], which can more truly and comprehensively reflect regional water utilization efficiency.

$$
\begin{gathered}
\min \rho=\frac{1+\frac{1}{m} \sum_{i=1}^{m} \frac{s_{i}^{-}}{x_{i k}}}{1-\frac{1}{q_{1}+q_{2}}\left(\sum_{r=1}^{q_{1}} \frac{s_{r}^{g+}}{y_{r k}^{g}}+\sum_{r=1}^{q_{2}} \frac{s_{t}^{b-}}{y_{r k}^{b}}\right)} \\
\text { s.t. } \sum_{j=1, j \neq k}^{n} x_{i j} \lambda j-s_{i}^{-} \leq x_{i k}, \sum_{j=1, j \neq k}^{n} y_{r j} \lambda_{j}+s_{r}^{g+} \geq y_{r k^{\prime}}^{g} \sum_{j=1, j \neq k}^{n} y_{t j}^{b}-s_{t}^{b-} \leq y_{t k}^{b} \\
1-\frac{1}{q_{1}+q_{2}}\left(\sum_{r=1}^{q_{1}} \frac{s_{r}^{g}}{y_{r k}^{g}}+\sum_{r=1}^{q_{2}} \frac{s_{r}^{b}}{y_{r k}^{b}}\right)>0, s^{-}>0, s^{b}>0, s^{g}>0, \lambda>0 \\
i=1,2, \cdots m ; r=1,2 \cdots q ; j=1,2 \cdots n(j \neq k)
\end{gathered}
$$

In the SE-SBM model (see Formula (1)), suppose the production system has $n$ decision-making units and each decision-making unit can be divided into $m$ inputs $(x), s_{1}$ desirable outputs $\left(y^{g}\right)$, and $s_{2}$ undesirable outputs $\left(y^{b}\right)$. Define the matrix $X, Y^{g}, Y^{b}$ as $X=\left[x_{1}, x_{2}, \cdots x_{n}\right] Y^{g}=\left[y_{1}^{g}, y_{2}^{g}, \cdots y_{n}^{g}\right], Y^{b}=\left[y_{1}^{b}, y_{2}^{b}, \cdots y_{n}^{b}\right]$. In addition, $s$ is the amount of slack in input and output, $\lambda$ is the weight vector, the objective function is $\rho$, and its value is between 0 and $1 . x_{i j}$ is the $i_{t h}$ input of the $j_{t h} \mathrm{DMU}$, and $y_{r j}$ is the $r_{t h}$ output of the $j_{t h}$ DMU. If, and only if, the decision-making unit's value is 1 , which is $s^{-}, s^{b}, s^{g}$ equal, then the decision-making unit is valid [22].

\subsection{Tobit Model}

The value of water utilization efficiency has a minimum value and is a distribution variable, belonging to truncated data or censored data. However, if the value of super-efficiency is directly used as the dependent variable for the least square regression analysis, the estimation of the parameters will be biased and inconsistent. The Tobit model adopts the maximum likelihood method to effectively solve this problem [23]. This measurement model can solve the problem of model construction of restricted dependent variables or truncated dependent variables. It consists of two types of equations: One is the selection equation that represents the constraints and the other is the continuous variable selection equation that satisfies the constraints. The Tobit model has been gradually applied to the estimation of driving factors such as innovation efficiency, carbon emission efficiency, and investment efficiency. The specific form is shown in Formula (2). The negative values of $y_{i}^{*}$ are replaced by 0 to reduce the deviation caused by regression. For example, Tong et al. studies the agricultural water efficiency in the Yangtze River Basin. At this time, the driving factors for water utilization efficiency are discussed in the Tobit model [24].

$$
y_{i t}^{*}=x_{i t}^{\prime} \beta+u_{i}+\varepsilon_{i t} S t . y_{i t}=\left\{\begin{array}{cc}
y_{i t}^{*} & \text { if } y_{i t}^{*}>0 \\
0, & \text { if } y_{i t}^{*} \leq 0
\end{array}\right.
$$




\section{Empirical Estimation}

\subsection{Measurement of Water Utilization Efficiency}

\subsubsection{Input-Output Indicators}

The paper integrates water resources, labor, and capital into factor inputs and takes economic benefits (GDP) and undesirable output (wastewater discharge) as output. The method of measuring capital stock used here is the perpetual inventory method. The calculation is based on the selection of a baseline year estimate and then the perpetual inventory method is used to calculate capital stock according to the constant price, which is proposed by Zhang et al. [25]. Due to China's current manufacturing power status and the promotion of higher education, this study only selects the total number of urban and rural employees at the end of the year to characterize regional labor input, no longer considering the issue of labor quality [26]. Here, the water consumption of each province and city is used as an indicator of water input, that is, the sum of industrial water, agriculture water, and domestic water, which is similar to water for tertiary industry. Desired output adopts real GDP of each province and city to represent (2006 as the base year), in order to make a vertical comparison of the production capacity of each province and city between 2000 and 2016 . To compare the GDP growth rate of each province and city horizontally, the total amount of wastewater discharge is selected as the undesirable output of water resources utilization. The data in this paper is derived from "China Statistical Yearbook", "Tibetan Statistical Yearbook", "China Water Resources Bulletin”, "Sichuan Statistical Yearbook", etc.

\subsubsection{Water Utilization Efficiency Results}

This paper uses the SE-SBM model considering undesirable output to measure the water utilization efficiency of Gansu, Qinghai, Yunnan, and Sichuan provinces where Tibet Autonomous Region and Tibetan regions are located and the relevant measurement process is completed by means of MAXDEA Pro 6.5. This paper set the efficiency measure to the output-oriented and non-radial modes and the proportion of the desirable output to the undesirable output is set to $1: 1$, that is, to put pollution emissions in the same position as economic growth. The results are shown in Table 1.

Table 1. Results of calculations of water utilization efficiency in the provinces where the Tibet Autonomous Region and the four provinces are located.

\begin{tabular}{cccccc}
\hline Year & Tibet & Yunnan & Sichuan & Qinhai & Gansu \\
\hline 2006 & 1.0052 & 0.9119 & 1.0155 & 0.7472 & 1.0241 \\
2007 & 1.0027 & 0.9160 & 1.0048 & 0.7642 & 1.0194 \\
2008 & 0.9903 & 0.9444 & 0.9397 & 0.7824 & 0.9710 \\
2009 & 1.0232 & 0.9521 & 0.9497 & 0.7740 & 0.9732 \\
2010 & 0.9890 & 0.9368 & 0.9929 & 0.7867 & 0.9838 \\
2011 & 0.9598 & 0.8222 & 1.0057 & 0.8194 & 0.9555 \\
2012 & 0.9979 & 0.8226 & 1.0080 & 0.8567 & 0.9665 \\
2013 & 1.0024 & 0.8511 & 1.0015 & 0.9112 & 0.9739 \\
2014 & 0.9885 & 0.8822 & 1.0106 & 0.9544 & 0.9815 \\
2015 & 0.9893 & 0.8872 & 1.0003 & 1.0040 & 0.9869 \\
2016 & 1.0345 & 0.9082 & 1.0355 & 1.0348 & 1.0210 \\
\hline
\end{tabular}

\subsection{Driving Factors Estimation}

\subsubsection{Influencing Factor Selection}

The explanatory variables here are to consider the utilization efficiency of water resources with undesirable output. The indicators of explanatory variables are as follows: (1) Regional economic growth, where the logarithm of per capita GDP is selected. Both water resource utilization and water 
pollution discharge will change with the level of regional economic development. This point was explained by the Environmental Kuznets Curve. In addition, the process of economic growth is also the process of industrial structure evolution and industrialization indicators are no longer selected here. (2) Regional environmental regulation, where industrial pollution control is used to complete the proportion of investment in regional industrial-added value. Stricter environmental regulations will produce "cost-abiding" and "backward emission reduction" and change the choice of enterprises [27]. (3) Urbanization level. Tibet is in a period of rapid urbanization and urbanization will affect the utilization of water resources through economic agglomeration, population agglomeration, factor agglomeration, investment pull, technology spillover, and other transmission mechanisms [28], but the specific direction and intensity need to be further tested. (4) Foreign direct investment, where the relative proportion of GDP is adopted. Foreign direct investment (FDI) plays a dual role of "angel" and "devil" in the utilization of regional water resources. It may be a "pollution halo" effect or "pollution haven" effect [29]. This paper will not discuss the same indicators of import and export that characterize the opening to the outside world. (5) The atmosphere of technological innovation, in which three patent authorizations per 10,000 people in the region are selected. This does not only represent the level of regional technological innovation to a certain extent, but is more about characterizing the region's atmosphere and spirit of technological innovation. (6) Resource endowment, where the logarithm of per capita water resources is selected. The more abundant the water resources are, the more likely the reverse "resource curse" will occur [30] and the more backward the production lifestyle and water resources management will be.

\subsubsection{Tobit Model Estimation}

The mixed panel Tobit regression and the random panel Tobit regression are studied. Whether they are random effects models depends on whether the random interference term $u_{i}$ is related to the explanatory variable $x_{i t}$. From the results in Table 2, Likelihood Ratio (LR) Test results in random panel Tobit regression estimates strongly reject " $H_{0}: \sigma_{\mathrm{u}}=0$ "; therefore, there are individual effects, so panel Tobit regression with random effects should be used.

Table 2. Estimation results of Tobit model for driving factors of water utilization efficiency.

\begin{tabular}{|c|c|c|c|c|c|c|c|c|}
\hline Variable & $\begin{array}{l}\text { Regression } \\
\text { Coefficient }\end{array}$ & $\begin{array}{l}\text { Standard } \\
\text { Deviation }\end{array}$ & $\begin{array}{c}\mathrm{T} \\
\text { Statistics }\end{array}$ & $p$ Value & $\begin{array}{c}\text { Regression } \\
\text { Coefficient }\end{array}$ & $\begin{array}{c}\text { Standard } \\
\text { Deviation }\end{array}$ & $\begin{array}{c}\mathrm{Z} \\
\text { Statistics }\end{array}$ & $p$ Value \\
\hline Estimation Type & \multicolumn{4}{|c|}{ Tobit Regression of Mixed Panel } & \multicolumn{4}{|c|}{ Random Panel Tobit Regression } \\
\hline Constant term & 1.104504 & 0.1498799 & 7.37 & 0.000 & 1.037337 & 0.216197 & 4.80 & 0.000 \\
\hline Per capita GDP & 0.0054618 & 0.0160068 & 0.34 & 0.734 & 0.0084181 & 0.0293599 & 0.29 & 0.774 \\
\hline $\begin{array}{l}\text { Environmental } \\
\text { regulation }\end{array}$ & 3.557068 & 1.666328 & 2.13 & 0.038 & 3.591043 & 1.673752 & 2.15 & 0.032 \\
\hline Urbanization & -0.6392587 & 0.041383 & -15.45 & 0.000 & -0.4806701 & 0.2479817 & -1.94 & 0.053 \\
\hline FDI & -4.79188 & 1.594217 & -3.01 & 0.004 & -5.378475 & 0.9091836 & -5.92 & 0.000 \\
\hline $\begin{array}{l}\text { Technological } \\
\text { innovation }\end{array}$ & 0.042004 & 0.0059436 & 7.07 & 0.000 & 0.0288158 & 0.0078741 & 3.66 & 0.000 \\
\hline $\begin{array}{c}\text { Resource } \\
\text { endowment }\end{array}$ & -0.0015381 & 0.0035078 & -0.44 & 0.663 & -0.0008486 & 0.0051246 & -0.17 & 0.868 \\
\hline /sigma & 0.0445306 & 0.0070937 & & & & & & \\
\hline /sigma_u & & & & & 0.0313059 & 0.0144678 & 2.16 & 0.030 \\
\hline /sigma_e & & & & & 0.0384703 & 0.0039672 & 9.70 & 0.000 \\
\hline LR & & & & & & & & \\
\hline
\end{tabular}




\section{Discussion of Results}

\subsection{Temporal and Spatial Differences in Water Utilization Efficiency}

On the whole, the regional water utilization efficiency in the study area showed a "U-shaped" trend in 2006-2016, which first decreased and then increased and also validated the existence of the "Environmental Kuznets Curve" [31]. Many countries or regions usually choose the road of pollution first and then treatment. Only when the economic development reaches a certain stage will the resources and demand for water environment treatment increase. The average utilization rate of water resources in these provinces decreased from 0.9408 in 2006 to 0.9125 in 2011 and then increased to 1.0068 in 2016. Compared with the eastern region, the water utilization efficiency of these Tibetan areas is still low, which has been verified by many scholars [32]. These provinces and regions are relatively backward in economic development. They undertake too many industries with high water consumption and high emissions in the inter-regional transfer of industries. Local governments will also relax environmental regulations for economic growth. To a certain extent, they act as "pollution havens" in the eastern and central regions, still repeating the old road of "pollution first and treatment later" in developed countries or coastal areas [33].

From the perspective of inter-provincial differences, the water utilization efficiency of Tibet, Sichuan, and Gansu in 2006 was greater than 1 . The water utilization efficiency of Yunnan and Qinghai was low, of which Qinghai was only 0.7472 . However, it should be noted that only the water utilization efficiency of Qinghai maintained a straight upward trend. In 2016, the water utilization efficiency of Qinghai had risen to 1.0348. From 2006 to 2016, the water utilization efficiency of Tibet Autonomous Region has been greater than or closer to 1 than that of the four provinces where Tibetan areas are located. Although it is only a comparison with Tibetan areas of the four provinces, we can still see the efforts Tibet has made to protect water resources and harness water environments. From the coefficient of variation, from 0.1246 in 2006 to 0.0942 in 2011 and then to 0.0551 in 2016, the water utilization efficiency of provinces and regions shows a convergence state and the inter-provincial water utilization efficiency continues to converge [34]. Spatial spillover effect exists in water resources utilization efficiency to a certain extent [35]. The process of inter-regional industry transfer is accompanied by technology transfer and spillover of water resource utilization while polluting industry transfer.

\subsection{Driving Factors Discussion}

(1) There is no significant positive or negative correlation between per capita GDP and water utilization efficiency, that is, there is no linear correlation between economic growth and water utilization efficiency in Tibet and other provinces from 2006 to 2016. This also conforms to the "Environmental Kuznets Curve", that is, the relationship between per capita income and environmental deterioration presents an inverted U-shaped trend and the improvement of water utilization intensity and the treatment of environmental pollution in the improvement of water resources efficiency also need the per capita gross domestic product (GDP) or the level of regional development to meet certain limits [36]. Although per capita GDP did not pass the significance test, the regression coefficient also shows that economic growth improves water utilization efficiency, which may be more due to the reduction of water intensity. Taking the Tibet Autonomous Region as an example, total water consumption declined slightly from 2006 to 2016, but it doubled from 3,252,000 tons in 2006 to 61,420,000 tons in 2016. The government should solve these problems in development, especially in green development, and choose the development path that suits the Tibetan areas.

(2) There is a significant positive correlation between environmental regulation and water utilization efficiency, that is, environmental regulation can effectively restrain the deterioration of water resource utilization. Scholars' relevant studies have also repeatedly shown that the government can promote enterprises to adopt more advanced production technology by implementing reasonable environmental policies and regulations, improving resource utilization efficiency, 
and reducing environmental pollution [37]. The intensity of environmental regulation in Tibet Autonomous Region, i.e., the proportion of investment in industrial pollution control, was much higher than that in other provinces and regions in 2013 and 2014, but the proportion of investment in governance in other years is low. The proportion of investment in industrial governance in Yunnan, Tibet, Sichuan, and other provinces is also declining. Investment in environmental governance has not increased with the same proportion of GDP. These provinces either pursue economic growth blindly by local governments or lack of local financial funds, but extensive economic growth is needed to regulate the development and utilization of water users by means of environmental regulation.

(3) The negative correlation between urbanization and water utilization efficiency is tested by significance. The rapid urbanization process leads to a significant increase in water consumption and water pollution discharge and an intensive utilization of resources. From 2006 to 2016, the urbanization of Tibet, Sichuan, Yunnan, Gansu, Qinghai, and other provinces has increased every year, but the urbanization of Tibet has been lagging behind other provinces, from $21.13 \%$ in 2006 to $29.56 \%$ in 2016 . However, we should pay more attention to the fact that Tibet is still largely a traditional farming and animal husbandry society with an extremely fragile ecological environment, weak urban development capacity, and limited population-gathering capacity. We could implement "the urbanization road of non-urbanization-oriented agricultural and pastoral areas" or "the development road of enriching the people and promoting Tibet with non-urbanization-oriented areas" [38]. At the same time, we should avoid urban areas becoming highly concentrated areas with water shortage, water environmental pollution, and water ecological destruction. On the other hand, the urbanization construction is conducive to the centralized treatment of sewage and increased production efficiency.

(4) There is a significant negative correlation between FDI and water utilization efficiency. Compared with the "technology halo", FDI brings more "pollution haven" [39]. From 2006 to 2016, the absolute value of FDI in these provinces and regions showed an inverted " $U$ " curve. Especially in Tibet, Qinghai, and other provinces and regions, FDI dropped sharply in 2015 and 2016. This could be because southeast Tibet, northwest Tibet, Sanjiang source, Yarlung Zangbo River, and other regions are restricted or prohibited by the state. However, it should be noted that Qilian Mountain is an important source of water in the Yellow River Basin and a national nature reserve; the problem of ecological environment destruction, especially water ecology, is prominent and is rooted in the inaction and inadequacy of local governments in environmental governance. Regional differences in environmental regulation policies also affect the layout of water-consuming, energy-consuming, and highly polluting industries, which are driven by local government interests and performance needs [40]. The government should strictly restrict high water consumption and high emission FDI and guide foreign investment into the green or high-tech industries.

(5) There is a significant positive correlation between technological innovation and water utilization efficiency. The improvement of water utilization efficiency must depend on the innovation and application of advanced water-saving and emission-reduction technologies [41]. From 2006 to 2016, the three patents granted by these provinces and autonomous regions grew rapidly, with Tibet increasing from 81 to 245 . However, the total number of patents granted by these provinces and autonomous regions is still much lower than that of other provinces per capita. Tibet Autonomous Region does not have full positive effect of technological innovation on water resource utilization, mainly due to the lack of high-level innovative talents and high-tech innovative industries, the lack of a good social environment for technological innovation, and adequate financial support. The crisis of resources and environment is closely related to technological change. Ecologization and greening of technological innovation have become the trend and value demand of its development. While developing the productive forces of modern society, the protection of water ecological 
environments should be taken into account, so as to enhance the labor productivity and the resource utilization.

(6) There is no significant correlation between per capita water resource ownership and water utilization efficiency, which means that there is no "resource curse "or" ratchet effect. In 2016, the utilization rate of water resources per capita in Tibet reached 141,746.56 cubic meters, 219 times as high as Gansu Province, 49 times as high as Sichuan Province, 32 times as high as Yunnan Province, and 13 times as high as Qinghai Province; its water resources and per capita water resources were ranked first in China. Although its engineering water shortage and water pollution in population gathering areas are serious, its unique industrial structure and sparse population characteristics also help it avoid the "resource curse" cycle, which also depends on the high altitude areas where water resources are abundant and population and economy do not accumulate too much. The theory of the "resource curse" has been constantly verified in some developing countries, but many domestic scholars have proposed that it needs unique industrial, cultural, economic, and social characteristics [42].

\section{Conclusions}

It is particularly necessary to understand the water utilization efficiency, development trends, and driving factors of Tibet and the Tibetan areas, while striving to build a national ecological security barrier for the Qinghai-Tibet Plateau. Considering the undesirable outputs, the SE-SBM model was used to measure the water resource utilization efficiency in Tibet, Sichuan, Yunnan, Gansu, and Qinghai from 2006 to 2016. The mixed and random panel Tobit model was used to empirically test the driving factors of water utilization efficiency in various provinces. From the dynamic evolution of water efficiency, the water utilization efficiency presented a decline and then a rising trend, which also implied the development path of treatment after pollution. However, the water utilization efficiency of Tibet Autonomous Region was higher than other research areas, while the government has made great efforts on its ecological protection and environmental governance issues. On the other hand, the water utilization efficiency in these regions still lagged behind the developed provinces and the water utilization efficiencies of Tibetan areas presented a constant convergence because of the space spillover effect.

Related to driving factors of water use efficiency, the regional development level and water utilization efficiency have not been significantly correlated in 2006 to 2016 and the wastewater discharge of Tibet has doubled. According to the empirical results, environmental regulation has effectively improved water utilization efficiency and reduced water pollution emissions. Urbanization has played a significant negative effect on water utilization efficiency, while the industry and population concentration would greatly consume water resources and discharge wastewater. Similarly for Tibetan areas, FDI has brought more negative effects and pollution haven rather than pollution aura, while the local government has undertaken too much backward production capacity. Development and application of water-saving and emission-reduction technologies would greatly improve water utilization efficiency and green development should not be separated from technological change and social progress in Tibetan areas. Due to the more abundant water resources, per capita possession, and special industrial structure, this has not had a negative effect on Tibetan areas or allowed the resource curse.

Therefore, the study recommends that the following measures should be taken. Firstly, local governments should select a new type of urbanization suitable for Tibetan plateaus, which should focus on improving the comprehensive urban carrying capacity and regional public service level, avoiding blind expansion, resource waste, and environment caused by urbanization. Secondly, the government should also put an end to the elimination of production capacity, high energy consumption, high emissions and other industries and encourage the introduction of high-tech industries and environmental protection industries so as not to pollute the environment, destroy the ecology, or waste resources. Thirdly, the provinces should strengthen their attention and support for technological 
innovation in Tibetan areas and strengthen the efficiency of conversion and application of current water-saving and emission-reduction technologies. Fourthly, the government should strengthen the coordinated management of water environment zones in Tibetan areas, build a trans-regional inter-basin water ecological compensation mechanism, strengthen the horizontal cooperation mechanism, and standardize the local government's race-to-bottom competition and their respective actions.

However, there are many unconsidered places which should be explored and discussed in future research. The ecological environment and climatic conditions in Tibetan areas are relatively fragile and the population dispersion distribution can cause serious engineering water shortages. Water conservancy projects in these areas are difficult to construct and it is difficult to recover destroyed water ecology. The study should consider its safety and risk of everyday waterworks practice and should also consider the deterioration in water quality and the cost analysis of water supply systems $[43,44]$. The simulation of the water supply system and case analysis of key areas should be adopted to solve these problems. In addition, the research should also consider the space spillover effect and inter-provincial synergy of water utilization efficiency and inter-regional industrial transfer may also have water pollution asylum problems [45]. Related to the driving factors, environmental regulation and FDI may play different roles in water utilization in different stages of economic development, so it is better to investigate the threshold effect and explore the specific action directions in different economic periods.

Author Contributions: Formal analysis, Z.Z. and F.W.; Investigation, Z.Z. and X.X.; Methodology, X.X.; Project Administration, X.D. and F.W.; Software, X.D. and X.X.; Writing-original draft, X.D.; Writing-review \& editing, X.D.

Funding: This research was supported by Jiangsu Social Science Fund (18GLC002), the China Postdoctoral Science Foundation (2017M621622) and the Fundamental Research Funds for the Central Universities (2018B23614).

Conflicts of Interest: The authors declare no conflict of interest.

\section{References}

1. Zuo, Q.T.; Hu, D.S.; Dou, M.; Zhang, X.; Ma, J.X. Framework and Core System of the Most Stringent Water Resource Management System Based on the Concept of Human-Water Harmony. Resour. Sci. 2014, 36, 906-912.

2. Wang, Z.Q.; Liu, C.S.; Liu, X.Y.; Zhou, X.H. Several Thoughts on Water ECO-Compensation Mechanism In Tibet. Resour. Environ. Yangtze Basin 2015, 24, 16-20.

3. Zhao, Z.R.; Xie, C.Q.; Dan, Q.; Fang, J.P. The valuation and dynamic forecast of eclogical fotprint of water resources in Tibet. J. Zhejiang Univ. (Sci. Ed.) 2015, 42, 559-566.

4. Shen, M.Y. Research on the Economic Development in Ecologically Fragile Nationality Area of South-west China and Farmers' Income Increase Approaches. Sichuan For. Explor. Des. 2012, 4, 105-114.

5. Wada, Y.; Gleeson, T.; Esnault, L. Wedge approach to water stress. Nat. Geosci. 2014, 7, 615-617. [CrossRef]

6. Pereira, L.S.; Cordery, I.; Iacovides, I. Improved indicators of water use performance and productivity for sustainable water conservation and saving. Agric. Water Manag. 2012, 108, 39-51. [CrossRef]

7. Frank, D.C.; Poulter, B.; Saurer, M.; Esper, J.; Huntingford, C.; Helle, G.; Treydte, K.; Zimmermann, N.E.; Schleser, G.H.; Ahlström, A.; et al. Water-use Efficiency and Transpiration across European Forests during the Anthropocene. Nat. Clim. Chang. 2015, 5, 579-583. [CrossRef]

8. Guan, X.J.; Liang, S.X.; Meng, Y. Evaluation of Water Resources Comprehensive Utilization Efficiency in the Yellow River Basin. Water Sci. Technol. 2016, 16, 1561-1570. [CrossRef]

9. Ding, X.H.; He, J.H.; Wang, L.Y. Inter-provincial water resources utilization efficiency and its driving factors considering undesirable outputs: Based on SE-SBM and Tobit model. China Popul. Resour. Environ. 2018, 28, 157-164.

10. Sun, D.Y.; Yu, J.W.; Liu, L.Y.; Wang, H.M. Efficiency evaluation for Industrial Water Use and Analysis of the Spatio-Temporal Differences in the Yangtze River Delta Urban Agglomeration. Resour. Environ. Yangtze Basin 2018, 27, 1901-1908.

11. Lu, X.; Xu, C.X. Study on Water Use Efficiency of The Yangtze River Economic Zone Based on Three-stage DEA and Malmquist Index Decomposition. Resour. Environ. Yangtze River Basin 2017, 26, 7-14.

12. Zhang, Y.X.; Xu, Z.S. Efficiency evaluation of sustainable water management using the HF-TODIM method. Int. Trans. Oper. Res. 2019, 26, 747-764. [CrossRef] 
13. Woodward, J.; Stoughton, K.M.; Begley, L.; Boyd, B. Evaluating Water Assets Using Water Efficiency Framework for Infrastructure Intensive Agency. J. Water Resour. Plan. Manag. 2019, 145, 04018090. [CrossRef]

14. Liu, B.Q.; Li, Y.Q.; Hou, R.; Wang, H. Does Urbanization Improve Industrial Water Consumption Efficiency? Sustainability 2019, 11, 1787. [CrossRef]

15. Ding, X.H.; Tang, N.; He, J.H. The Threshold Effect of Environmental Regulation, FDI Agglomeration, and Water Utilization Efficiency under Double Control Actions-An Empirical Test Based on Yangtze River Economic Belt. Water 2019, 11, 452. [CrossRef]

16. Nazari, B.; Liaghat, A.; Akbari, M.R.; Keshavarz, M. Irrigation water management in Iran: Implications for water use efficiency improvement. Agric. Water Manag. 2018, 208, 7-18. [CrossRef]

17. Sun, C.Z.; Gao, X.W.; Zhao, L.S. The Driving Effect of "Four Modernizations" on Green Efficiency of Water Resources in China. J. China Univ. Geosci. (Soc. Sci. Ed.) 2018, 18, 58-67.

18. Ma, Y. An Empirical Study on the Impact of Urbanization on Water Resource Utilization Efficiency in Arid Areas: Based on DEA Model and IPAT Model. Technol. Econ. 2016, 35, 85-90.

19. Bao, C.; Chen, X.J. Spatial Econometric Analysis on Influencing Factors of Water Consumption Efficiency in Urbanizing China. J. Geogr. Sci. 2017, 27, 1450-1462. [CrossRef]

20. Cabrera, E.; Estruch-Juan, E.; Molinos-Senante, M. Adequacy of DEA as a regulatory tool in the water sector. The impact of data uncertainty. Environ. Sci. Policy 2018, 85, 155-162. [CrossRef]

21. Fan, H.; Zhou, D.Q. On the Total Factor Energy Efficiency with Undesirable Outputs in China. J. Appl. Stat. Manag. 2012, 31, 1084-1096.

22. Qian, Z.; Liu, X.C. Environmental Regulation and Green Economy Efficiency. Stat. Res. 2015, 32, $12-18$.

23. Arouna, A.; Dabbert, S. Determinants of Domestic Water Use by Rural Households Without Access to Private Improved Water Sources in Benin: A Seemingly Unrelated Tobit Approach. Water Resour. Manag. 2010, 24, 1381-1398. [CrossRef]

24. Tong, J.P.; Ma, J.F.; Wang, S. Agricultural Water Use Efficiency in the Yangtze River Basin: Based on Super Efficiency DEA and Tobit Mode. Resour. Environ. Yangtze River Basin 2015, 24, 603-608.

25. Zhang, J.; Wu, G.Y.; Zhang, J.P. The Estimation of China's provincial capital stock: 1952-2000. Econ. Res. J. 2004, 10, 35-44.

26. Jie, H.; Wang, C.Y. Education Investment, Labor Quality and Economic Growth-Based on STR Model. J. Cent. China Norm. Univ. (Humanit. Soc. Sci.) 2019, 58, 50-56.

27. Zhang, H.; Wei, X.P. Green Paradox or Forcing Emission Reduction: Double Effects of Environmental Regulations on Carbon Emissions. Popul. Resour. Environ. China 2014, 24, 21-29.

28. Kan, D.X.; Lu, L.J. Study on the Impact of Urbanization on Water Resources Utilization in China: Based on Water Footprint Perspective and Spatial Dynamic Panel Data. Shanghai Econ. Res. 2017, 12, 37-84.

29. Marconi, D. Environmental Regulation and Revealed Comparative Advantages in Europe: Is China a Pollution Haven. Rev. Int. Econ. 2012, 20, 616-635. [CrossRef]

30. Wang, Y.X.; Wang, H.M.; Liu, G. Spatial Distribution Analysis of Resource Curse Based on Ecological Priority-A Case Study of the Yellow River Basin. Soft Sci. 2019, 33, 50-55.

31. Kong, Y.S.; Khan, R. To Examine Environmental Pollution by Economic Growth and Their Impact in an Environmental Kuznets Curve (EKC) among Developed and Developing Countries. PLoS ONE 2019, 14, e0209532. [CrossRef] [PubMed]

32. Zhou, D.; Zhou, F.N. Inspection, Measurement and Interpretation of Club Convergence of Water Resources Utilization Efficiency in China: 2003-2015. J. Nat. Resour. 2018, 33, 1103-1115.

33. $\mathrm{Xu}, \mathrm{Z} . W$. Industrial Economic Development, Environmental Regulation Intensity and Emissions Reduction Effect: Theoretical Analysis and Empirical Test Based on Development Pattern of Treatment after Pollution. J. Financ. Econ. 2016, 42, 134-144.

34. Zang, Z.; Zou, X.Q. Test on Convergence Trait of Water Resource Intensity in Mainland China: An Empirical Research Based on Panel Data at Provincial Level. J. Nat. Resour. 2016, 31, 920-935.

35. Zhao, L.S.; Sun, C.Z.; Zhen, D.F. Water resource utilization efficiency and its spatial spillover effects measure in China. Acta Geogr. Sin. 2014, 69, 121-133. [CrossRef]

36. Zhao, Z.X.; Wang, T.; Hinrich, V.; Yan, Y.F. China's Carbon Emission Inflection Point Prediction Based on The Classical Environmental Kuznets model. Financ. Trade Econ. 2013, 10, 81-88.

37. Brisbois, M.C.; de Leo, R.C. State Roles and Motivations in Collaborative Approaches to Water Governance: A Power Theory-based Analysis. Geoforum 2016, 74, 202-212. [CrossRef] 
38. Shi, Y.F. New Urbanization in Tibet: Current Situation, Characteristics and Path. J. Tibet. Univ. Natl. (Philos. Soc. Sci. Ed.) 2016, 37, 51-56.

39. Javorcik, B.S.; Spatareanu, M. Does it Matter Where you Come from? Vertical Spillovers from Foreign Direct Investment and the Origin of Investors. J. Dev. Econ. 2011, 96, 126-138.

40. Zhang, F.; Song, X.N.; Xue, H.F.; Dong, H.Z. Decoupling Relationship and Dynamic Response between Environmental Regulation, Technological Progress and Industrial Water Intensity. Popul. Resour. Environ. China 2017, 27, 193-201.

41. Costantini, V.; Mazzanti, M. Environmental Performance, Innovation and Spillovers: Evidence from a Regional NAMEA. Ecol. Econ. 2013, 89, 101-114. [CrossRef]

42. Zhong, C.L.; Hu, X.P. The Impact of Natural Resource Endowment on Regional Ecological Efficiency. J. Dalian Univ. Technol. (Soc. Sci. Ed.) 2016, 37, 19-26.

43. Rak, J.R.; Pietrucha-Urbanik, K. An Approach to Determine Risk Indices for Drinking Water-Study Investigation. Sustainability 2019, 11, 3189. [CrossRef]

44. Pietrucha-Urbanik, K.; Studziński, A. Case Study of Failure Simulation of Pipelines Conducted in Chosen Water Supply System. Eksploat. Niezawodn. Maint. Reliab. 2017, 19, 317-323. [CrossRef]

45. Daniel, J.R.; Pinel, S.L.; Brooks, J. Overcoming Barriers to Collaborative Transboundary Water Governance Identifying Local Strategies in a Fragmented Governance Setting in the United States. Mt. Res. Dev. 2013, 33, 215-224. [CrossRef]

(C) 2019 by the authors. Licensee MDPI, Basel, Switzerland. This article is an open access article distributed under the terms and conditions of the Creative Commons Attribution (CC BY) license (http://creativecommons.org/licenses/by/4.0/). 